\title{
LncRNA MAGI2-AS3 is down-regulated in intervertebral disc degeneration and participates in the regulation of FasL expression in nucleus pulposus cells
}

\author{
Shuting Cui ${ }^{\dagger}$, Zizhen Liư ${ }^{\dagger}$, Bin Tang, Zhizhen Wang ${ }^{*}$ and Baojian Li
}

\begin{abstract}
Background: It is known that Fas ligand (FasL) is involved in the development of intervertebral disc degeneration (IDD). A recent study reported that InCRNA MAGI2-AS3 up-regulated the expression of FasL to promote breast cancer. Therefore, we investigated the roles that IncRNA MAGI2-AS3 might play in IDD.

Methods: A total of 66 IDD patients (IDD group) and 58 healthy volunteers (Control group) were recruited in this study. Quantitative real-time PCR (qRT-PCR) and western blot were used to investigate gene expression levels. Cell transfections were carried out to analyze gene interactions. The diagnostic value of IncRNA MAGI2-AS3 for IDD was assessed by ROC curve analysis.

Results: The expression levels of plasma IncRNA MAGI2-AS3 were lower in IDD patients compared to that in the control group. Down-regulation of IncRNA MAGI2-AS3 effectively distinguished IDD patients from the control group. The expression levels of plasma IncRNA MAGI2-AS3 were significantly increased after the treatments. Over-expression of IncRNA MAGI2-AS3 inhibited the expression of FasL, while the silencing of IncRNA MAGI2-AS3 promoted the expression of FasL in nucleus pulposus (NP) cells.
\end{abstract}

Conclusions: Therefore, InCRNA MAGI2-AS3 is down-regulated in IDD and participates in the regulation of FasL expression in nucleus pulposus (NP) cells.

Keywords: Intervertebral disc degeneration, IncRNA MAGI2-AS3, Fas ligand

\section{Background}

Intervertebral disc degeneration (IDD) is a common bone disease that causes lower back pain [1]. IDD is generally considered as the first step of degenerative spinal changes [2]. The development and progression of IDD inevitably leads to disc narrowing, the formation of osteophytes and spinal stenosis [3, 4]. Although various risk factors such as age and obesity have been identified for IDD, the molecular mechanisms of the pathogenesis of this disease are still largely unknown [5]. The incidence of IDD is predicted to be significantly increasing

\footnotetext{
* Correspondence: zdjdk59@163.com

+Shuting Cui and Zizhen Liu contributed equally to this work.

Department of Orthopedics, Liaocheng second People's Hospital, No. 306 Health Street, Linqing City, Shandong Province 252600, People's Republic of China
}

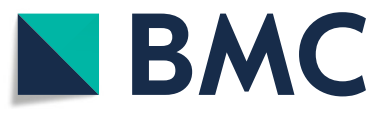

(c) The Author(s). 2020 Open Access This article is distributed under the terms of the Creative Commons Attribution 4.0 International License (http://creativecommons.org/licenses/by/4.0/), which permits unrestricted use, distribution, and reproduction in any medium, provided you give appropriate credit to the original author(s) and the source, provide a link to the Creative Commons license, and indicate if changes were made. The Creative Commons Public Domain Dedication waiver (http://creativecommons.org/publicdomain/zero/1.0/) applies to the data made available in this article, unless otherwise stated.

in near future due to lifestyle changes [6]. Therefore, understanding the pathogenesis of IDD is urgently needed to improve treatments of this disease.

Fas ligand (FasL), a member of the tumor necrosis factor family, is a type-II transmembrane protein that can induce cell apoptosis [7]. FasL-induced apoptosis also plays essential roles in the development of IDD [8]. In effect, inhibition of FasL provides new insights into the treatment of IDD [9]. In some cases, FasL interacts with long non-coding RNAs (lncRNAs) to achieve its functions [10]. LncRNAs are a group of non-protein coding RNAs with critical functions involved in various human diseases [11]. It has been reported that lncRNA MAGI2AS3 can up-regulate FasL to participate in the development of breast cancer [12], indicating the potential involvement of lncRNA MAGI2-AS3 in IDD. In this study 
we showed that IncRNA MAGI2-AS3 was downregulated in IDD and negatively regulated the expression of FasL in nucleus pulposus (NP) cells.

\section{Methods \\ Patients}

A total of 66 patients with IDD (IDD group, 36 males and 30 females, with the age of 42 to 76 years old and $58.6 \pm$ 4.8 years old, respectively) and 58 healthy volunteers (control group, 31 males and 27 females, with the age of 40 to 77 years and $58.0 \pm 5.4$ years old, respectively), who were admitted by the Liaocheng Second People's Hospital from January 2016 to October 2017, were included in this study to serve as research subjects. Inclusion criteria of patients are as follows: 1) patients were diagnosed and treated for the first time; 2) complete medical records; 3 ) patients who completed treatment in Liaocheng Second People's Hospital; 4) patients were willing to participate with signed consent form. Exclusion criteria of patients are as follows: 1) patients were diagnosed with multiple diseases; 2) patients were treated before admission. The 58 healthy volunteers received systemic physiological examinations in Liaocheng Second People's Hospital and all physiological parameters were within the normal range. No significant differences in age and gender were found between the patients and the control groups. This study was approved by the Ethics Committee of Liaocheng Second People's Hospital.

\section{Specimens and nucleus pulposus (NP) cells}

Fasting blood $(5 \mathrm{ml})$ was extracted from each patient and healthy control 1 day after admission and on the day of discharge. Blood samples were used to prepare plasma samples using the conventional method. NP cells were isolated and cultivated according to the methods described by Wang et al. [13]. Cells were collected from passage $3-5$ for subsequent experiments.

\section{qRT-PCR}

To detect the expression of lncRNA MAGI2-AS3, total RNAs were extracted using the TRIzol reagent (Thermo Fisher Scientific). Reverse transcription was performed using the AMV Reverse Rranscriptase (Gibco; Thermo Fisher Scientific). The PCR reaction systems were prepared using the PowerUp ${ }^{\mathrm{m} w}$ SYBR $^{\mathrm{m} w}$ Green Master Mix (Applied Biosystems $^{\mathrm{mt}}$ ). Primers of lncRNA MAGI2-AS3, FasL and the endogenous control GAPDH were synthesized by GenePharma (Shanghai, China). The expression levels of lncRNA MAGI2-AS3 and FasL were normalized to GAPDH and were calculated according to the $2^{-\Delta \Delta C q}$ method [14]. .

\section{Vectors and cell transfection}

Vectors expressing lncRNA MAGI2-AS3 and empty vectors were designed and constructed by Sangon (Shanghai,
China). The Lipofectamine 2000 reagent (Invitrogen, Thermo Fisher Scientific) was used to perform cell transfections with $10 \mathrm{nM}$ vectors. Cells that were treated with Lipofectamine 2000 reagent only was used as control (C). Transfection with empty vectors was used as negative control (NC).

\section{Western blotting}

To detect the protein expression of FasL, total proteins were extracted using the RIPA solution (Thermo Fisher Scientific). Protein samples were denatured and 10\% SDS-PAGE electrophoresis was performed. Proteins were then transferred to PVDF membranes. After blocking in 5\% non-fat milk for $1 \mathrm{~h}$, incubation with primary antibodies of rabbit anti-human FasL (1:1000; cat. no. ab15285; Abcam) and anti-GAPDH (1,1000; cat. no. ab8245; Abcam) was performed. Membranes were further incubated with IgG-HRP secondary antibody (goat anti-rabbit, cat. no. sc-2004; Santa Cruz Biotechnology, Dallas, TX, USA). Signals were produced using ECL Western Blotting Substrate (Pierce; Thermo Fisher Scientific). Membranes were scanned using the iBright Imaging Systems Thermo Fisher Scientific). Image J v1.48 was used for data analysis.

\section{Statistical analysis}

Three biological replicates were included in each experiment. Data were expressed as mean \pm standard deviation (SD) and were processed using the GraphPad Prism 6 software. Comparisons between IDD and the control group were performed by unpaired t-test. Comparisons between pre-treatment and post-treatment levels of plasma lncRNA MAGI2-AS3 were performed by paired t-test. Comparisons among 3 groups were performed by ANOVA (one-way) and Tukey test. Diagnostic value of lncRNA MAGI2-AS3 for IDD was evaluated by receiver operating characteristic (ROC) curve. Differences with $p<0.05$ were statistically significant.

\section{Results}

Plasma levels of IncRNA MAGI2-AS3 were altered in IDD patients

Plasma levels of IncRNA MAGI2-AS were assessed by qRT-PCR in both IDD patients and healthy people. Compared to the control, plasma levels of lncRNA MAGI2-AS3 were significantly lower in IDD patients (Fig. $1, p<0.01$ ).

\section{Plasma IncRNA MAGI2-AS3 is a potential diagnostic biomarker for IDD}

Diagnostic value of IncRNA MAGI2-AS3 for IDD was evaluated by ROC curve analysis with IDD patients as true positive cases and healthy people as true negative cases. The area under the curve was 0.90 , with the standard 


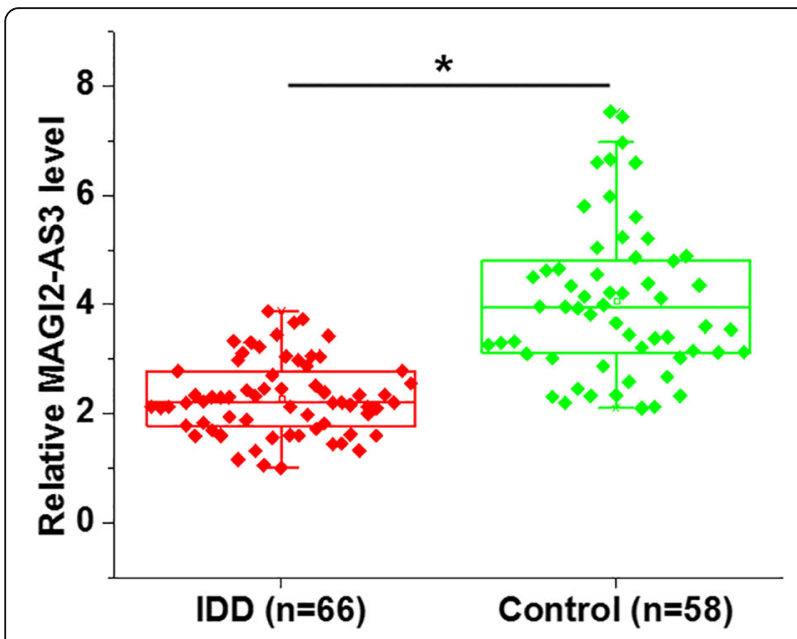

Fig. 1 Plasma IncRNA MAGI2-AS3 was significantly down-regulated in IDD patients. QRT-PCR results showed that plasma levels of InCRNA MAGI2-AS3 were significantly higher in IDD patients than that in healthy people $\left({ }^{*}, p<0.01\right)$

error of 0.027 and $95 \%$ confident interval of $0.84-0.95$ (Fig. 2).

\section{Plasma IncRNA MAGI2-AS3 levels were significantly increased after treatment}

Results of qRT-PCR showed that the plasma levels of lncRNA MAGI2-AS3 were significantly increased after treatment compared with the pre-treatment levels ( $p<0.05$, Fig. 3 , ). Therefore, monitoring the levels of plasma circulating IncRNA MAGI2-AS3 may reflect the treatment outcomes.

LncRNA MAGI2-AS3 negative regulated the expression of FasL in NP cells

Over-expression and knockdown of MAGI2-AS3 were achieved in NP cells, and expression of FasL was detected by qRT-PCR and western blot. Compared to the control

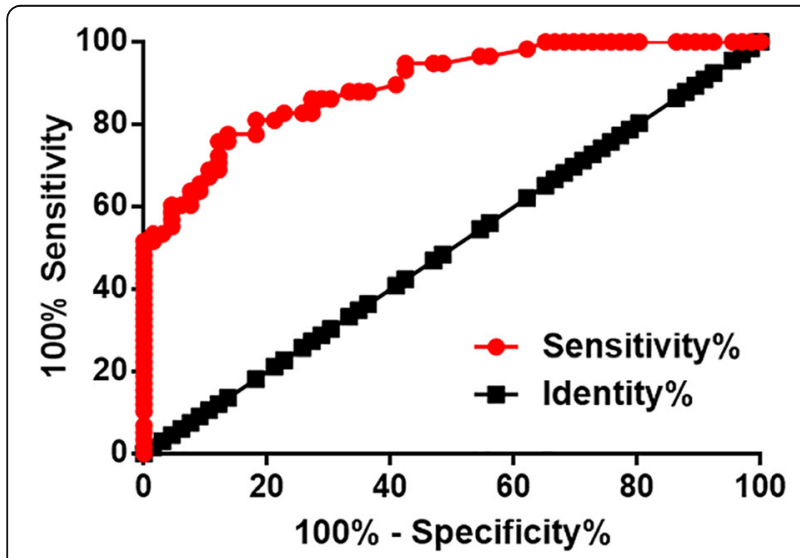

Fig. 2 Plasma InCRNA MAGI2-AS3 is a potential diagnostic biomarker for IDD. ROC curve analysis showed that down-regulation of IncRNA MAGI2-AS3 effectively distinguished IDD patients from healthy people

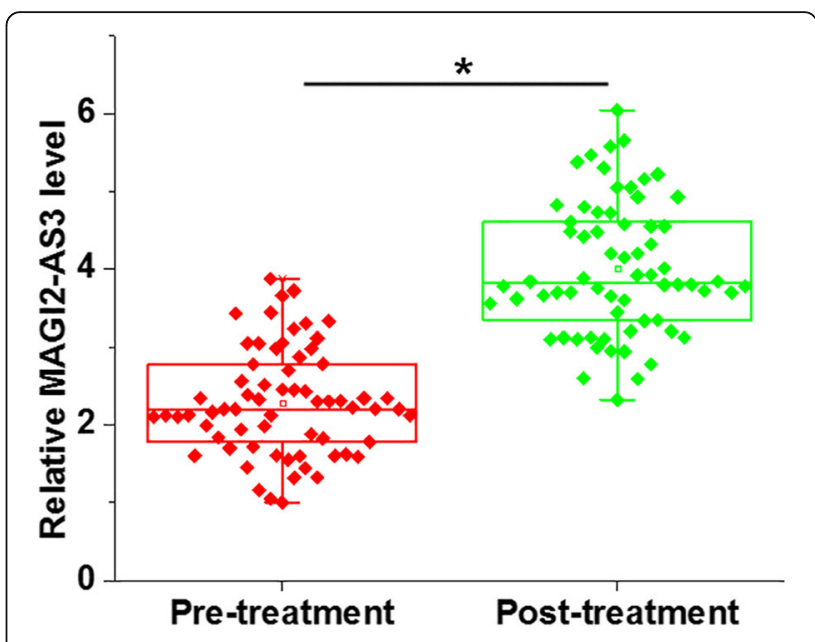

Fig. 3 Plasma IncRNA MAGI2-AS3 levels were significantly increased after treatment. QRT-PCR results showed that plasma levels of IncRNA MAGI2-AS3 were significantly increased in IDD patients after treatment compared to that of pre-treatment levels $\left({ }^{*}, p<0.05\right)$

(C) and negative control (NC) groups, over-expression of lncRNA MAGI2-AS3 resulted in inhibited expression of FasL in NP cells at both mRNA and protein levels (Fig. 4a, $p<0.05)$. In the contrary, knockdown of lncRNA MAGI2AS3 played an opposite role (Fig. 4b, $p<0.05$ ).

\section{Discussion}

IDD is a common bone disease with unclear pathogenesis. The key findings of the present study are that lncRNA MAGI2-AS3 was down-regulated in IDD, and over-expression of MAGI2-AS3 may improve IDD by down-regulating FasL, which promotes IDD.

The development of IDD is a complex process with multiple internal and external factors involved. Genomewide transcriptome analysis showed that the development of IDD is characterized by an altered expression pattern of a large set of lncRNAs [15], indicating the involvement of lncRNAs in these diseases [16]. MAGI2AS3 is a recently identified lncRNA with tumor suppression functions in breast cancer and bladder cancer [12, 17]. In the present study, we showed that plasma circulating MAGI2-AS3 was significantly down-regulated in IDD patients, and down-regulation of MAGI2-AS3 effectively distinguished IDD patient from healthy people. Those findings indicated the involvement of MAGI2AS3 in IDD, and the potential diagnostic values of circulating MAGI2-AS3 for IDD. However, more clinical trials are needed to further confirm our findings.

NP is the inner core of the vertebral disc, and the elastic inner structure confers vertebral disc the ability to withstand forces of torsion and compression. Accelerated NP cell apoptosis promotes IDD [18]. During the development of IDD, FasL mediates the apoptosis of NP cells, which in turn aggregates disease conditions [13]. 

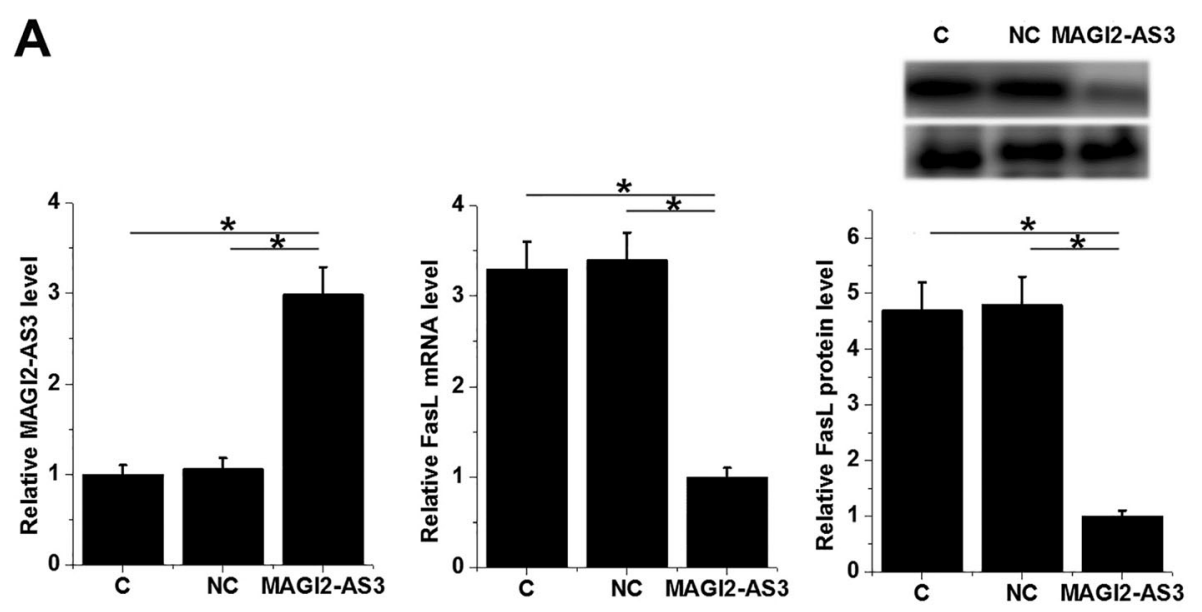

B
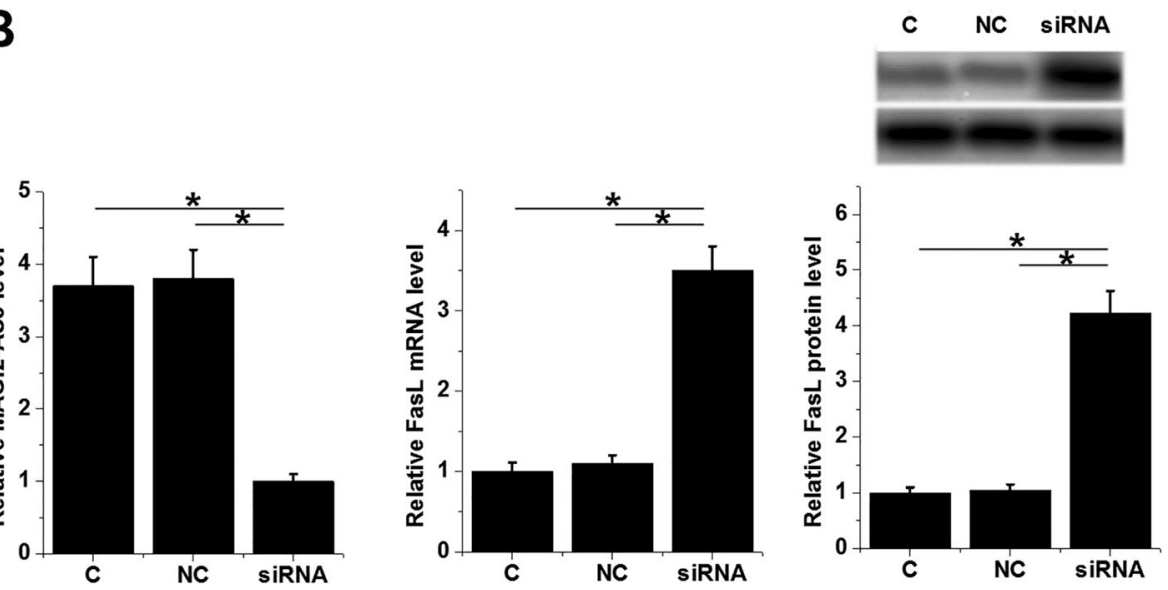

Fig. 4 LnCRNA MAGI2-AS3 negative regulated the expression of FasL in NP cells. Results of GRT-PCR and western blot showed that overexpression of IncRNA MAGI2-AS3 inhibited (a) the expression of FasL, while IncRNA MAGI2-AS3 siRNA silencing promoted (b) the expression of FasL in NP cells $(*, p<0.05)$

In the development of breast cancer, lncRNA MAGI2AS3 inhibited cancer cell growth by inhibiting FasL [12]. Our results showed that MAGI2-AS3 negatively regulated FasL in NP cells. Therefore, over-expression of MAGI2-AS3 may assist the treatment of IDD by inhibiting FasL.

It is worth noting that in this study we only detected gene expression in plasma, while may not reflect the gene expression status in intervertebral disc tissues. Our future study will try to include intervertebral disc tissue samples to further confirm the dysregulation of MAGI2AS3 in IDD. In addition, our patients included in this study were all Han Chinese. It is known that ethnicity may also affect gene expression [19]. The roles of MAGI2-AS3 in IDD among different populations should be further explored. Moreover, in vitro experiments of animal model are also expected in future studies to verify the in vivo functions of MAGI2-AS3 in the development of IDD.

\section{Conclusion}

In conclusion, lncRNA MAGI2-AS3 is down-regulated in IDD and participates in the regulation of FasL expression in NP cells.

\section{Abbreviations}

FasL: Fas ligand; IDD: Intervertebral disc degeneration; IncRNAs: Long noncoding RNAs; NP: Nucleus pulposus; qRT-PCR: Real-time quantitative PCR

\section{Acknowledgments}

Not applicable.

\section{Authors' contributions}

STC and ZZL: experimental work, data analysis, research design and manuscript writing. BT and BJL: experimental work and manuscript writing. ZZW: data analysis, research design and manuscript writing. All authors read and approved the final manuscript.

Funding

No funding received. 


\section{Availability of data and materials}

The datasets generated and/or analysed during the current study are available in the Baidu Netdisk repository, https://pan.baidu.com/s/1 19XDotFfXyBYravOddKxjg [ACCESSION NUMBER TO DATASETS: a7mw].

\section{Ethics approval and consent to participate}

Ethical approval was obtained from the Ethics Committee of Liaocheng Second People's Hospital. All procedures performed in studies involving human participants were in accordance with the ethical standards of the institutional and national research committee. Written informed consent was obtained from all individual participants included in the study.

\section{Consent for publication}

Not applicable.

\section{Competing interests}

The authors declare that they have no competing interests.

Received: 24 January 2019 Accepted: 22 January 2020

Published online: 06 March 2020

\section{References}

1. Gore M, Sadosky A, Stacey BR, Tai KS, Leslie D. The burden of chronic low back pain: clinical comorbidities, treatment patterns, and health care costs in usual care settings. Spine (Phila Pa 1976). 2012;37(11):E668-77.

2. Boos N, Weissbach S, Rohrbach H, Weiler C, Spratt KF, Nerlich AG. Classification of age-related changes in lumbar intervertebral discs: 2002 Volvo award in basic science. Spine (Phila Pa 1976). 2002:27(23):2631-44.

3. Kirkaldy-Willis WH, Farfan HF. Instability of the lumbar spine. Clin Orthop Relat Res. 1982;165:110-23.

4. Ahn TJ, Lee SH, Choi G, Ahn Y, Liu WC, Kim HJ, et al. Effect of intervertebral disk degeneration on spinal stenosis during magnetic resonance imaging with axial loading. Neurol Med Chir (Tokyo). 2009;49(6):242-7 discussion 7.

5. Le Maitre CL, Freemont AJ, Hoyland JA. The role of interleukin-1 in the pathogenesis of human intervertebral disc degeneration. Arthritis Res Ther. 2005;7(4):R732-45.

6. Capoor MN, Ruzicka F, Machackova T, Jancalek R, Smrcka M, Schmitz JE, et al. Prevalence of Propionibacterium acnes in intervertebral discs of patients undergoing lumbar microdiscectomy: a prospective cross-sectional study. PLoS One. 2016;11(8):e0161676.

7. Griffith TS, Brunner T, Fletcher SM, Green DR, Ferguson TA. Fas ligandinduced apoptosis as a mechanism of immune privilege. Science. 1995; 270(5239):1189-92.

8. Chen SQ, Lin JP, Zheng QK, Chen SJ, Li M, Lin XZ, et al. Protective effects of paeoniflorin against FasL-induced apoptosis of intervertebral disc annulus fibrosus cells via Fas-FasL signalling pathway. Exp Ther Med. 2015;10(6): $2351-5$

9. $\mathrm{Ma}$ CJ, Liu X, Che L, Liu ZH, Samartzis D, Wang HQ. Stem cell therapies for intervertebral disc degeneration: immune privilege reinforcement by Fas/ FasL regulating machinery. Curr Stem Cell Res Ther. 2015;10(4):285-95.

10. Huang D, Chen J, Yang L, Ouyang Q, Li J, Lao L, et al. NKILA IncRNA promotes tumor immune evasion by sensitizing $T$ cells to activationinduced cell death. Nat Immunol. 2018;19(10):1112-25.

11. Shi $X$, Sun $M$, Liu $H$, Yao $Y$, Song $Y$. Long non-coding RNAs: a new frontier in the study of human diseases. Cancer Lett. 2013;339(2):159-66.

12. Yang $Y$, Yang $H, X u M$, Zhang $H$, Sun $M, M u ~ P$, et al. Long non-coding RNA (IncRNA) MAGI2-AS3 inhibits breast cancer cell growth by targeting the Fas/ FasL signalling pathway. Hum Cell. 2018;31(3):232-41.

13. Wang $H Q$, Yu XD, Liu ZH, Cheng X, Samartzis D, Jia LT, et al. Deregulated miR-155 promotes Fas-mediated apoptosis in human intervertebral disc degeneration by targeting FADD and caspase-3. J Pathol. 2011;225(2):23242.

14. Livak KJ, Schmittgen TD. Analysis of relative gene expression data using real-time quantitative PCR and the 2(-Delta Delta C(T)) method. Methods. 2001;25(4):402-8.

15. Wan ZY, Song F, Sun Z, Chen YF, Zhang WL, Samartzis D, et al. Aberrantly expressed long noncoding RNAs in human intervertebral disc degeneration: a microarray related study. Arthritis Res Ther. 2014;16(5):465.

16. Chen Y, Ni H, Zhao Y, Chen K, Li M, Li C, et al. Potential role of IncRNAs in contributing to pathogenesis of intervertebral disc degeneration based on microarray data. Med Sci Monit. 2015;21:3449-58.
17. Wang F, Zu Y, Zhu S, Yang Y, Huang $W$, Xie $H$, et al. Long noncoding RNA MAGI2-AS3 regulates CCDC19 expression by sponging miR-15b-5p and suppresses bladder cancer progression. Biochem Biophys Res Commun. 2018:507(1-4):231-5.

18. Dimozi A, Mavrogonatou E, Sklirou A, Kletsas D. Oxidative stress inhibits the proliferation, induces premature senescence and promotes a catabolic phenotype in human nucleus pulposus intervertebral disc cells. Eur Cell Mater. 2015;30:89-102 discussion 3.

19. Li X-F, Yin X-H, Cai J-W, Wang M-J, Zeng Y-Q, Li M, et al. Significant association between IncRNA H19 polymorphisms and cancer susceptibility: a meta-analysis. Oncotarget. 2017;8(28):45143-53.

\section{Publisher's Note}

Springer Nature remains neutral with regard to jurisdictional claims in published maps and institutional affiliations.
Ready to submit your research? Choose BMC and benefit from:

- fast, convenient online submission

- thorough peer review by experienced researchers in your field

- rapid publication on acceptance

- support for research data, including large and complex data types

- gold Open Access which fosters wider collaboration and increased citations

- maximum visibility for your research: over $100 \mathrm{M}$ website views per year

At BMC, research is always in progress.

Learn more biomedcentral.com/submissions 